\title{
On the Borrowability of Body Parts
}

\author{
Kelsie Pattillo \\ Lecturer of Linguistics, Department of Linguistics, University \\ of Wisconsin-Milwaukee, Milwaukee, Wisconsin, USA \\ kelsie@uwm.edu
}

\begin{abstract}
Within recent years, quantitative cross-linguistic research has shown that body parts are one of the least borrowed semantic fields (Tadmor and Haspelmath, 2009a; 2009b; Tadmor, 2009). With body parts showing many similarities to closed classes, it is simple to assume there is little motivation for a language to borrow body part terms into its lexicon. Yet, despite its lower percentage of borrowings cross-linguistically, some languages employ much higher percentages of borrowings for naming the body. The motivations behind such borrowings across languages remain unexplored but can largely be explained by social factors. As Thomason and Kaufman (1988) and Thomason (2008) claim, social factors generally trump linguistic factors as predictors of contact-induced change. This study first discusses proposed inhibitions to lexical borrowing and then examines cases of body part loanwords from various languages showing how they fit into social patterns motivating such borrowings.
\end{abstract}

\section{Keywords}

body parts - borrowings - loanwords - calques - social motivation

\section{Introduction}

Although languages do not need to borrow terms for body parts, some studies claim loanwords for body parts are frequent (Brown, 1999; 2001) including linguistic areas such as Meso America (Campbell, Kaufman and Smith-Stark, 1986), the Lower Mississippi Valley (Kaufman, 2014) and Croatia (Vrzić and Doričić, 2014). Despite these claims, there is quantitative evidence that 
indicate cross-linguistically, languages borrow terms for the body far less frequently than other semantic fields. Tadmor and Haspelmath (2009a; 2009b) and Tadmor (2009) show that among twenty-four semantic fields, the body ranks third lowest in percentage of loanwords when the numbers are averaged among more than forty different languages in their sample. Given the low frequency of lexical borrowing for body part terms when compared to other semantic fields, it is not clear what the motivating factors for doing so are. This presents a conflict exemplifying typologically unusual structures: languages borrow terms for body parts, yet they are not borrowed frequently. As Harris (2010: 91) writes about typologically unusual structures, "rare and unusual structures pose a challenge for linguists. On the one hand, linguists must explain why they are rare or unusual; on the other hand, they must explain, given the rarity, why they exist at all." This leads to two guiding research questions, which I address in this paper and are given below.

1. Why do languages borrow body parts less frequently than other semantic fields?

2. What, given these factors, motivates languages to borrow words for body parts?

First, I consider factors that influence the rate of borrowing for loanwords as presented in Vejdemo and Hörberg (2016), including word frequency, word class, semantic factors, and language entrenchment. I show how these factors relate to body parts as a semantic field and discuss why body parts are borrowed less frequently than other semantic fields, as has been quantitatively shown by the case studies that contributed to the World Loanword Database (Haspelmath and Tadmor, 2009a). Then, I present cases of body part borrowings and discuss other factors that motivate such borrowing, including social and pragmatic factors. Specifically, this study considers the social motivations for languages to borrow terms for body parts and how these patterns align with current claims in body part studies following Thomason and Kaufman's (1988) claim that social factors trump linguistic factors as predictors of contact-induced change. It also considers pragmatic factors as another motivating source for borrowing.

The paper begins with a discussion of motivation to borrow body parts and background literature on body part borrowability in Section 2. A description of the factors that may inhibit body part borrowings appear in Section 3. Section 4 introduces cross-linguistic cases of body part borrowings arranged by social motivation and Section 5 provides further discussion. A short conclusion appears in Section 6. Many of the data presented here come from body part literature and are cited accordingly. The examples from English, German, and Irish come from my own knowledge of the languages and their etymology. Rather than focus solely on my own examples from Western European 
languages, I have opted to include data from many different families and geographic areas.

\section{$2 \quad$ Background}

At first glance, it seems that languages would have very little reason to borrow terms for body parts. It is widely assumed that all languages have a set of terms to refer to the body, thus any body part named by a loanword could be assumed to be a luxury loan or non-catachrestic innovations (see Onysko and Winter Froemel, 2011). In fact, body part vocabulary is a common semantic field included in an assumed core list of basic vocabulary found across languages. For example, Wierzbicka (2007) and Wierzbicka and Goddard (2018) claim body parts are a universal semantic prime. Likewise, many descriptive grammar projects begin with elicitations of the 100-word long Swadesh List (Swadesh, 1952), which includes twenty human body parts. Because humans share the same set of body parts regardless of the language(s) they speak, there are no novel parts to name. From this it can be assumed that body parts make up a closed class in that language speakers will not suddenly discover new body parts and need vocabulary to name them. Tadmor (2009) expresses this sentiment in describing why languages are hesitant to borrow lexemes belonging to the semantic field 'the body'. He states, "They consist of concepts that are universally shared by most human societies. Practically every language can be expected to have indigenous words for such concepts, and therefore has no need to borrow them" (p. 65). In a similar vein, Haspelmath (2009: 36) states, "the best-known generalization about lexical borrowing is the constraint that "core vocabulary" is very rarely or never borrowed." However, as Haspelmath (2009) points out, languages do not necessarily borrow words due to need: they already have linguistic resources to create new words without borrowing them and languages borrow words to replace terms they already have (p. 35). Thus, lexical borrowings are not limited to nouns of objects that do not already exist within a speaker community but can also include lexical classes with very few members, such as pronouns. For example, Heine and Kuteva (2008) show examples of the rise of politeness pronouns in European languages as a contact-induced process, as taken from Helmbrecht's (2005) data. Although various factors may inhibit lexical borrowings, Helmbrecht's (2005) data demonstrate motivations may play a stronger role than inhibitions in contact situations.

As stated above in the introduction, Haspelmath and Tadmor (2009a) systematically show that among twenty-four different semantic fields, 'the body' is 
the third least frequent source of loanwords in forty-one languages. This ranking comes from averaging the percentages found in each semantic field across all languages in the study and further reported in the World Loanword Database (Haspelmath and Tadmor, 2009b), which was a multi-year comparative project aimed at identifying cross-linguistic stability of lexemes across semantic fields. Prior to the in-depth study led by Haspelmath and Tadmor, body parts were commonly believed to be stable terms in a language's lexicon cross-linguistically. Holdman et al. (2008) examine terms from the 100-word and 200-word Swadesh lists for stability across languages, finding that the 100-word Swadesh list is stable over time. Among the body parts included on the list, ear, liver, eye, hand, tooth, breasts, bone and tongue are listed within the top twenty most stable words cross-linguistically. This is convincing data to support the claim that words that are stable cross-linguistically are resistant to borrowing.

In analyzing a speaker community's potential motivation to borrow or not borrow terms for body parts, it is necessary to ask what is meant by 'body part.' In its simplest definition, body parts are divisions of the body, but not all divisions of the body have a name, are used in everyday speech, or are salient features for languages speakers. For example, the 'head' is more salient in shape and function than the 'ear canal'. Thus, when discussing cross-linguistic tendencies with body parts as a semantic field, there is an assumption that the body parts considered are "major body parts", or ones that all speakers of a language use and have a concept for. Frequently, these major body parts are also extended to non-corporeal objects through metonymy, metaphor, and grammaticalization. Here, I adopt a working definition of "body part" to mean a referent to a conceptual unit of the human body. The terms considered in this paper are consistent with other studies on body parts: in general, they are salient and widely included in body parts listed in descriptive grammars and dictionaries developed and used by linguists. The word lists given in the individual chapters of the World Loanword Database (Haspelmath and Tadmor, 2009b) also appear in the Intercontinental Dictionary Series (Key and Comrie, 2015) and frequently appear in language documentation software such as FLEx or Lexique Pro. Given the method of data collection, I assume that the words given in my sources typically reflect casual usage, but the style of speech where a body part term is used could be considered. Despite the concreteness of the human body, its high saliency, and the frequency with which body part terms appear in grammars and dictionaries, defining exactly what is included in concepts like the 'head' and where specific body parts start and stop is complex.

Although humans share the same set of body parts, there is widespread discussion of variation in the division of the body across languages. Some studies (e.g., Andersen, 1978; Majid et al., 2006; Majid, 2010) focus on partonymic 
relations whereas others focus on polysemy (e.g., Brown and Witkowski, 1983; Wilkins, 1996). Andersen (1978) suggests a hierarchy for naming parts of the body by grouping body parts according to saliency in part-whole relations. More recently, the case studies in Majid et al's (2006) special issue of Language Sciences claim that there are speech communities without concepts of 'body,' or 'head,' which are otherwise typically held to be conceptual universals (see Wierzbicka, 2007). The case studies in Majid et al. as well as Majid (2010) demonstrate that languages vary in how body parts are divided in the lexicon. Further, studies on body part polysemy (e.g., Brown, 2005a; 2005b; Brown and Witkowski, 1983; Wilkins, 1996; Witkowski and Brown, 1985) typically demonstrate variation in the division of the body by naming more than one part with the same term. For example, the term meaning 'hand' refers to the entire upper limb in many languages, but only the outer end of the upper limb on many others. In other languages, the term for 'hand' may refer to the part of the upper limb between the elbow and fingertips. Additionally, although terms for so-called "major" or "basic" body parts such as 'head' and 'hand' are commonly morphologically simplex across languages and used with high frequency, Gąsiorowski (2017) claims neither 'head' nor 'hand' were stable terms in Proto Indo-European, accounting for a wide range of non-cognate terms across branches of the Indo-European family. These studies suggest having a lexeme for a concept implies the conceptualization of that notion, but not in the reverse: conceptualization does not necessarily entail lexicalization. Additionally, these studies indicate that although the human body is a conceptual universal, contact situations motivate negotiating meaning that may include reconceptualizing the body, which has the potential to motivate loanword adoption. Outside of body parts, such processes have been described within pragmatic frameworks (see Winter Froemel, 2014).

In addition to differences in conceptualizations and divisions of the body, dictionaries and word lists found in descriptive grammars often only list one term for one body part. This leads to a bias that there is only one word, or perhaps one proper or pragmatically neutral word, for each body part. For example, if a language uses the same word to refer to both the hand and the arm, one might assume that the language has no term meaning 'arm but not hand' or 'hand but not arm'. As Kraska-Szlenk (2014) points out, Polish and Swahili have both hand/arm and foot/leg polysemy. Although Polish ręka refers to the entire upper limb, there are also unambiguous terms to refer to the hand only, when needed. For example, dton 'hand' for no specific shape or function, garść 'closed hand' as when holding something, pięść 'fist'. The same applies to Swahili for which Kraska-Szlenk provides kiganja, kitanga, and kitengele '(open/closed) hand' and gnumi, sumbwi, and konde 'fist' (p. 23). Likewise, English has both the terms head 
and noggin to refer to the same part of the body. Although these word pairs from Polish, Swahili, and English refer to the same physical part of the body respectively, their usage, extensions, and frequency within the language are not equal. Thus, it is important to consider not only word lists and dictionary entries for considering the frequency of loanword borrowings, but also corpus data, which can show language in use. Assuming that there is only one (proper) word for each body part may cause one to overlook loan borrowings. I discuss this in more detail at the end of Section 3 and with data in Section 4. Determining the "basic" term may involve examining which body parts become embedded in a language through processes such as grammaticalization or metaphorical extension. This leads to the following question which is further discussed in Section 5. Do changes such as grammaticalization and metaphorical extension only occur to the more frequently used term or do speakers tend to differentiate the meaning of the "competing" terms and extend them differently?

There is also a belief that terms for body parts are more stable diachronically than other semantic fields (see Holman et al., 2008; Tadmor, 2009). Nonetheless, we should not assume that body part terminology does not change over time. Multiple studies on body parts show historical changes of body part nomenclature (see Gąsiorowski, 2017; Pattillo, 2014; Hilpert, 2007; Brown, 2005a; 2005b; Krefeld, 1999; Wilkins, 1996; Witkowski and Brown, 1985). Body part polysemy is common cross-linguistically and is often assumed to be a stage of historical change (see Sweetser, 1990). In addition to hand arm, finger hand, and foot leg polysemy, languages also extend body parts to non-adjacent parts. For example, in both English and German, the term for 'cheek' is also extended to refer to the fleshy part of the buttocks (English: cheek, butt cheek; German: Backe, Pobacke). Sometimes the target of the extension becomes the primary referent for the lexeme, creating a motivation for speakers to use a new term to refer to the trigger of the extension. For example, English toe (cognate with Latin digitus) once referred to both sets of digits on the upper and lower limbs but is now restricted to the digits on the lower limbs. Although still quite old in English's lexicon, the word finger is newer than toe. In this example, the newer word comes from a Germanic root, but it is just as possible that speakers could have chosen to borrow a term from another language.

Haspelmath and Tadmor (2009b) show that speakers across languages typically borrow terms for body parts with much less frequency than most other semantic fields. Here I address my first guiding research question. 
1. Why do languages borrow body parts less frequently than other semantic fields?

There are multiple characteristics that potentially make body parts resistant to borrowing. As discussed in Section 2, body parts are considered basic vocabulary of languages. Thomason and Kaufmann (1988:6) state that as basic vocabulary is the traditional criterion for establishing genetic linguistic relations, there is a widespread assumption that terms belonging to basic vocabulary are more resistant to borrowing than other linguistic features; however, this does not hold in contact situations as demonstrated in pidgins and creoles. Thus, it is necessary to identify other inhibiting factors. Besides basic vocabulary, frequency, age of a lexeme, and semantic factors also play a role in lexical replacement. Vejdemo and Hörberg (2016) explore the following semantic factors in their study on lexical replacement: mutual information, arousal, imageability, and senses. I address each of these below in relation to how they apply to body parts as a semantic field.

\subsection{Frequency}

Gąsiorowski (2017: 102) claims body parts are resistant to borrowings due to their high frequency of use, their "basic" character and diachronic conservation. Compared to other semantic fields, major body parts appear with high frequency in language use. Their "basic" character refers to the fact that they appear in all languages, as discussed in the previous section. It is necessary to distinguish here how major body parts have different frequencies than other body parts. For example, both 'ear' and 'ear lobe' appear as lexemes in the vocabulary list of the World Loanword Database (Haspelmath and Tadmor, $2009 \mathrm{~b})$, but these two terms appear with much different frequencies in the Corpus of Contemporary American English. 'Ear' appears 30,723 times in the corpus, whereas 'earlobe' appears 398 times (COCA, 2O2O). Beyond their corporeal references, English speakers use 'ear' metaphorically and metonymically, but do not extend 'earlobe' in this way. These extensions impact the frequency of not only 'ear' in English, but arguably the frequency of many major body parts in daily language use across the world's languages. Both Pagel et al. (2007) and Vejdemo and Hörberg (2016) show that frequency plays a significant role in lexical replacement, concluding that the more frequently a word is used, the less likely it is to be replaced by another lexeme. This implies that terms for major body parts are not just resistant to being replaced with loan borrowings, but also with language internal lexical formation processes. 


\section{2}

\section{Age of a Lexeme}

Another proposed factor of loanword resistance is the age of a lexeme. According to Tadmor (2009), age plays a role in resistance to borrowing as examples of survival.

The longer a word exists in a language, the greater the opportunity it has to be replaced by a loanword. If a word has existed in a language for thousands of years without being replaced by a loanword, this clearly indicates high resistance to borrowing. On the other hand, if a word has only existed for a few years, it is not possible to tell whether it is borrowing-resistant: given sufficient time, it might be replaced by a loanword. Therefore, old words constitute much more reliable evidence for resistance to borrowing than new words (Tadmor, 2009: 66).

In other words, lexemes that have existed longer in a language are less likely to be borrowed or replaced with other lexical items. As stated at the end of Section 2 above, body parts are generally assumed to be stable across languages. As part of a language's core vocabulary, body parts are often older words in a given language and this shows that they have been resistant to borrowings or lexical replacement over a long period of language use.

\subsection{Semantic Factors}

Along with frequency and age of a lexeme, Vejdemo and Hörberg (2016) analyze semantic factors that influence lexical replacement. The factors considered in their analysis include mutual information (in which two words frequently co-occur such as in metaphors, idioms, and collocations), how easy it is to picture a lexical item in the mind, and the number of synonyms for a lexical item. Although their study does not directly analyze borrowings, its findings are important to the discussion here because it suggests characteristics that lead to openness to replacing lexical items. Body parts are interesting for applying Vejdemo and Hörberg's (2016) findings because they are typically easily pictured in the mind and deeply entrenched into language. Numerous studies on the embodiment theory demonstrate how cross-linguistically, languages extend major body parts to non-corporeal targets. Works such as Kraska-Szlenk (2014) show how this occurs in many languages with many body part sources extending to many non-corporeal targets, whereas collected volumes such as Maalej and Yu (2011), Sharifian et al. (2008), or Kraska-Szlenk (2019a) demonstrate case studies of specific body part extensions within particular languages. In many of these case studies, the high imageability of body parts plays a role in the cognitive processes involved in metonymic and 
metaphorical extensions of body parts. For example, languages often map the location of a body part within the body to refer to locations within an object (such as an automobile) or landscape (such as a mountain or body of water). Interestingly, it is not only external body parts that are imageable in this way. Internal organs, such as the heart or liver also undergo frequent semantic extension, including locations (such as English $a$ heart of an artichoke $=$ the middle of an artichoke and the guts of a paper = the core content of a paper). Additionally, body parts frequently collocate with other lexemes (consider, for example, English heart and soul). Vejdemo and Hörberg (2016) found that the more mutual information a lexeme contained, the less likely it was to be replaced. Likewise, the more imageability a lexeme had, the less likely it was to be replaced. For body parts, which are both highly entrenched in language and have high imageability, there are multiple factors which make them resistant to replacement.

Of all semantic factors considered, Vejdemo and Hörberg (2016) found that synonymy plays the most influential role in lexical replacement. Although Vedejmo and Hörberg do not make this connection, synonymy indicates an openness to loanwords in intense language contact situations. Whereas dictionaries and word lists may list one word for many body parts, pragmatic analyses may show more synonyms for body parts than in traditional methods. Higher numbers of body part synonyms may correspond to euphemisms and taboo or pragmatic features. I address each of these in Section 4 below. Taboo and euphemism suggest cultural or social factors that may influence which words speakers replace in a given language, demonstrating that any potential constraint is not immune to social factors, as Thomason and Kaufmann (1988) and Thomason (2008) claim. In the next section I show numerous examples of borrowed terms for body parts and demonstrate how social factors play a key role.

Browsing through the collection of loan borrowings coded for the semantic field the body in the World Loanword Database (henceforth WOLD) clearly demonstrates that the body is not a common target for borrowings cross-linguistically (Haspelmath and Tadmor, 20ogb). Nevertheless, the percentages of body part loans vary among the languages. Although the body as a semantic field overwhelmingly ranks among the lowest semantic fields among the twenty-four semantic fields examined, there is a large range in the percentages of body part loans. For example, Iraqw and Gawwada have very low percentages of body part 
loans at $3.1 \%$ and $2.7 \%$, respectively. In contrast, $29.5 \%$ of the words listed in the body vocabulary for Tarifiyt Berber are loans and $42.4 \%$ of Gurindji's body part vocabulary listed are loans. I include a table in the appendix listing all languages in the woLD vocabulary database with their percentages of body part terms as loanwords and the semantic fields they rank above in percentage of loanwords. In the appendix, I also include a full list of terms of the body used in WOLD, which are based on a previous list used for the Intercontinental Dictionary Series (Richie Key and Comrie, 2015). Here, I list the ten languages in the sample with the highest percentages of loanwords in their vocabulary lists for the body.

Selice Romani (57.2\%), Gurindji (42.4\%), Romanian (39.2\%), Saramaccan $(35.2 \%)$, Thai $(30.4 \%)$, Tarifiyt Berber (29.5\%), Japanese (29.2\%), Indonesian $(24.2 \%)$, English (28.1\%), Ceq Wong $(21.9 \%)$

Additionally, loanwords replace or coexist with some body parts more than others. For example, twenty of the forty-one languages in the WOLD sample have loanwords to refer to genitalia, but only six have loanwords listed for 'heart'.

I now turn to my second guiding research question.

2. What, given these factors, motivates languages to borrow words for body parts?

My analysis focuses on social factors as motivations for borrowings and considers pragmatic factors as well. Haspelmath (2009) provides the following social and attitudinal factors for the likelihood of borrowings: prestige of the donor language, puristic attitudes, taboo, homonymy, avoidance, and new concepts adopted from another culture. Except for puristic attitudes, which I interpret to mean an overt intent to avoid borrowings, I address each of these factors with examples in the following subsections. In addition to using cited examples from WOLD, I also include my own examples.

\subsection{Prestige of the Donor Language}

In many contact situations, there is a clear case of prestige and subordinate culture. Especially when speakers of one language or language variety exert overt power over another group, the prestige is easy to identify. Many examples of body part loan borrowings come out of such cases, including loan borrowings from Chinese into Japanese, Arabic into Tarifiyt Berber, Old Norse and French into English, and English into Irish. Examples (1-4) below demonstrate such borrowings. The lists are a sample of loan borrowings selected to show a variety of body part terms including organs, parts of the face and head, and more from clear cases of prolonged prestige languages. When available, I have 
included information about the borrowing's register and the result of the borrowing.

Japanese

(1) Loan Borrowing

hifu 'human skin' zugaikotsu 'skull' nō 'brain' jida 'ear, earlobe' haizō 'lung'

Donor
Language
Chinese
Chinese
Chinese
Chinese
Chinese

\author{
Register Result \\ general coexistence \\ general replacement \\ general replacement \\ formal coexistence \\ general replacement
} (Schmidt, 2009)

Tarifiyt Berber

(2) Loan Borrowing s'siffat 'face' rmuxx 'brain' azağğif'head' ssanšrat 'spine'

$\begin{array}{ll}\text { Donor Language } & \text { Result } \\ \text { Arabic } & \text { coexistence } \\ \text { Arabic } & \text { coexistence } \\ \text { Arabic } & \text { replacement } \\ \text { Arabic } & \text { no data }\end{array}$

(Kossmann, 2009)

English

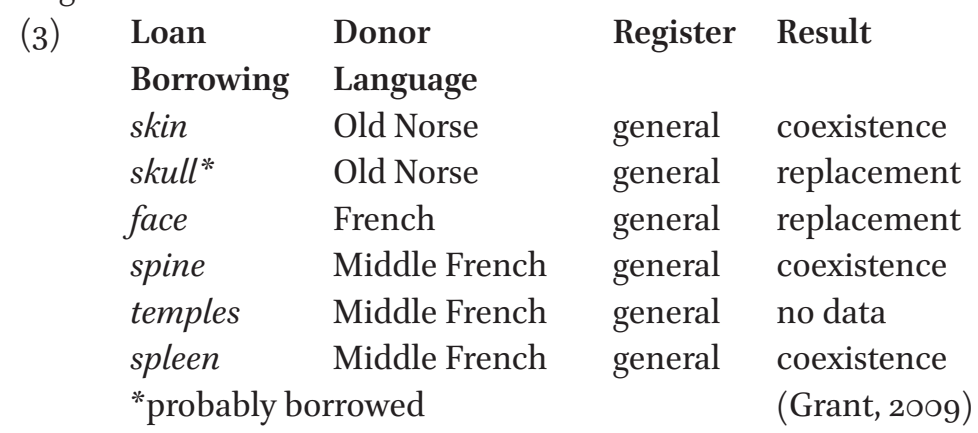

The examples listed in (1-3) above demonstrate that loan borrowings occur for naming both external and internal body parts. Especially with the examples given for naming the ear, face, head, and skin, saliency does not seem to play an obvious role in resistance to borrowing. The examples also show that body part borrowings may both replace and coexist with native lexemes. Irish rosta 'wrist' is an example of such a pattern. Borrowed from English, rosta is a newer term for referring to the wrist, first appearing in dictionaries published in the mid to late 1900 s and likely invented for the artificially created standard 
language. Irish also has other terms that coexists with rosta for referring to this part of the body; however, the native terms are morphemically complex. These are given in (4) below.

Irish terms for wrist

(4) a. rosta 'wrist'

b. bunrí [base of the forearm] 'wrist'

c. caol an duirn [slenderness of the fist] 'wrist'

d. caol na láimhe [slenderness of the hand/arm] 'wrist'

At present, all four terms exist in Irish for referring to the wrist. Speakers then have a choice in which term they wish to use. Although the prestige of English in Ireland has introduced a loanword for 'wrist', pragmatic factors will influence which term a speaker uses. For example, in Irish immersion courses aimed at preserving Irish, the terms in (4b-d) may be used but in daily conversation, the frequency of each term differs. In the Corpus of Contemporary Irish, rosta occurs fifty-one times, whereas caol na láimhe occurs five times. Caol an duirn and bunrí do not appear in the corpus (CCI, 2020).

In addition to contact situations in which one group controls another, prestige comes in other forms including education and social class. An obvious source of loans for many European languages is Latin and Greek, especially for medical terminology. In general, Latin and Greek terms served as a lingua franca through their prestige in the development of Western medicine. Likewise, Chinese has had a strong influence in the development of Eastern medicine. This influence can be seen in modern body part terms in both Japanese and Vietnamese. Of the 104 body part meanings listed in WOLD for the body, it is noteworthy that 12 are Latin terms that demonstrate loans due to this prestige. These meanings are listed in (5) below.

Latin borrowings listed as head words in WOLD

(5) pubic hair, artery, molar, nasal mucus, intestines, tendon, testicles, penis, vagina, vulva, perspire, vomit.

Of the meanings listed in (5) above, it is interesting to compare the meaning with the vocabulary given for English as a language in WOLD. For example, the Latin loanword perspire is listed as the gloss, but Germanic sweat is the only term given in the English vocabulary list. Although sweat is more frequent and a better candidate for the basic vocabulary term, perspire holds prestige in English. Pragmatically, perspire is more polite than sweat. The English saying "horses sweat, men perspire, women glow" demonstrates politeness factors in these words and their referents. Despite the differences in politeness, 
the Corpus of Contemporary American English shows 19,504 occurrences for sweat but only 161 occurrences for perspire and 1265 for perspiration and 18 for anti-perspirant (COCA, 2O2O). The same politeness contrast holds for nasal mucus / snot and vomit / puke, which also have multiple other terms in English that could compete for basic vocabulary (for example booger). In the case of testicle, penis, vagina, and vulva, the social prestige of Latin also is elevated due to taboo, which I discuss in the next section.

Social class, social prestige, and register also interact in loanword adoption. Thai provides a clear example of how social class also plays a role in social prestige and body part vocabulary. Thai has a royal register with its own set of body part terminology reserved for referring to the king. Many of the body part terms in this register may also be used poetically and are predominantly loans from Sanskrit. A sample of these terms appear in (6) below.

\begin{tabular}{lll}
\multicolumn{3}{l}{ Example loanwords into Thai's Royal Register } \\
nêet & 'eye' & Sanskrit \\
phaahăa & 'arm' & Sanskrit \\
hàt, kəon & 'hand' & Sanskrit \\
day & 'hand' & Khmer \\
phlao & 'leg' & Khmer \\
baathaa, bàat & 'foot' & Sanskrit \\
š̌s & 'neck' & probably borrowed \\
sirú, š̌an & 'head' & Sanskrit
\end{tabular}

(Suthiwan, 2009)

Although borrowings for body parts may not be as frequent as other semantic fields, these data show examples of how languages borrow body parts in contact situations due to language prestige. In many cases, language prestige is clear but also complex. The examples I discuss here are not exhaustive, but rather they discuss various aspects of how social prestige leads to loanword adoption. They demonstrate how social prestige plays an important role in motivating borrowings for body part terms.

\subsection{Taboo}

In addition to adopting a loanword to show social prestige of a donor language, language speakers also use loanwords to refer to the body in order to avoid taboo vocabulary. Body parts vary in their social roles across languages. For example, in many parts of the world, there are different social rules for the feet and the head. In many places, sitting with one's feet pointed towards another person is rude. Touching the top of someone's head may also be taboo. Enfield (2006: 188) explains the low social ranking the feet have in Lao culture 
and states the Lao word tiing 'foot' is often avoided. According to Enfield, Lao speakers may use the word khaas 'leg' to avoid saying tiing 'foot.' Although languages may avoid taboos by using terms for other body parts or accessing different registers, speakers of some languages also use loanwords to avoid taboo. For example, Adelaar (1996: 489-49o) identifies six basic body part terms from Malagasy that have been borrowed from Malay: voavitsy 'calf of the leg', molotra 'lip', sofina 'outer ear', valahana 'loins', tratra 'chest', and lamosina 'back'. The reason for the borrowing is not clear, but Adelaar provides two possible explanations: either social devaluation or a social taboo leading to socially stratified speech styles (p. 49o). Although terms for any body part have the potential of becoming taboo in any language, the body parts that seem to be commonly taboo across languages are genitals and reproduction as well as death, which I turn to next.

Analyzing the borrowed scores listed for body parts in WOLD, it is not surprising that loanwords are most common cross-linguistically among body parts for terms for the genitals. The highest cross-linguistic borrowed scores of body part vocabulary in WOLD are for 'vagina' at .34, 'vulva' at .32 and womb at .29. Male genitalia follow closely with borrowability scores of .29 for penis and .21 for testicles. For comparison, the score given to the nose is .03 and the eyelid is .04. In English, it is extremely taboo to refer to genitalia using native Germanic terms, especially to refer to female genitalia. Thus, the Latin loans of vagina and vulva are the only socially acceptable terms that speakers can use in most settings requiring speakers to refer to these specific body parts. In addition, English also has multiple loanwords to avoid saying the word ass or butt (ocks). The French loan derriere is most widely used as a polite term, perhaps due to French's social prestige in English; however, Yiddish has contributed tokus and tush $(y)$ as casual options and Polish has contributed dupa in areas around the Midwest of the United States with high concentrations of Polish immigrants. Within the Corpus of Contemporary American English, $\operatorname{tush}(y)$ has the most occurrences at 501 of these loanwords for the buttocks, derriere has 199, tokus has 11 and dupa has 2 (COCA, 2020). These examples exemplify the high number of synonyms for taboo vocabulary, demonstrating the relationship between synonymy and lexical replacement introduced in Vejdemo and Hörberg (2016) and briefly discussed at the end of Section 3 above.

Although the numbers in the English corpus data above are relatively low, they demonstrate that English speakers use many different words to refer to the buttocks in everyday speech. The selection of which word they use in which situation is influenced by both pragmatic and social factors. Pizarro 
Pidraza (2018) found that word choice varies among Spanish speakers referring to body parts and physiological processes associated with human reproduction. Pizarro Pidraza's analysis shows both internal and social factors influence speaker's word choice. Internal factors included sex of the concept (such as masculine or feminine), and topic of the question asked in 54 interviews conducted for data collection. Social factors included age group, education level and stance towards taboo. Using direct construals, such as literal or dictionary entries, to refer to human reproduction convey an intention of straightforwardness whereas indirect construals, such as metonymy, metaphor, taxonomical shifts, or generic expressions, marked semi-conversational styles, talking about everyday life, and as euphemistic functions (p. 265). Thus, loanwords provide both direct and indirect construals for speakers to choose from when referring to taboo objects.

Across the languages in WOLD, the word for 'corpse' was also frequently borrowed. Ten of the forty-one languages in WOLD's sample used loanwords for 'corpse.' This is not surprising as death is a common source of taboo. Besides referring to a dead body as a concept of itself, the taboo also frequently includes homonymy in which a word sounds like a taboo word. In some Australian languages, speakers replace everyday words with borrowed terms for so-called mother-in-law codes, whereas in other circumstances words become taboo because they sound too similar to a deceased person's name. These two social taboos are also sources for loanwords referring to body parts. For example, Dixon (1990) provides Dyirbal mala and Yidiny mandi as examples for 'hand' as terms that can be used in other languages or dialects for avoidance styles. Some of the other body parts that have avoidance styles include 'anus', 'thigh', 'hair', 'tooth', 'body', and 'stomach.'

Besides avoiding taboo words, there may also be social situations in which speakers borrow terms specifically for pejoration to socially distance themselves from other groups. For example, alongside nose, English also has borrowed the words schnoz and schnozzle from Yiddish. Although these examples are used more frequently with less formal registers than more common basic vocabulary, they are still clear examples of loans. In most cases, the words schnoz or schnozzle can replace nose in a sentence, but it adds a jocular or even negative tone to the reference to the nose. These two Yiddish loans differ from nose in that they can specifically be used to refer to a large or unattractive nose. This is also emphasized in metaphors, in which replacing nose with schnoz emphasizes the undesired action in metaphors such as in (7) below. Producing (7b) is stronger than (7a) in its negative evaluation of one's actions, but it could also be used to express humor. 
(7) a. sticking your nose in someone else's business

b. sticking your schnoz(zle) in someone else's business

'To become involved in something that should not include you.'

These examples show that there are multiple sources for social taboo that motivate borrowings to refer to body parts, and that a wide variety of body parts can become taboo. Besides serving a politeness function or change in register, loanwords used to replace taboo words or for pejoration demonstrate a broader pragmatic function. Whereas loanwords adopted for prestige or to express new concepts adopted from another culture are more neutral lexical choices, those borrowed for taboo or pejoration demonstrate strong pragmatic effects. This supports Winter Froemel's (2014) claim that "processes of borrowing are much more heterogeneous and complex than traditional dictionary-based studies suggest" (p. 66) and that loanwords frequently undergo narrowing of meaning or adopt new meanings in the recipient language. This also demonstrates how corpus studies can return different findings of loanword usage for semantic fields such as 'the body' than traditional dictionary-based methods.

\subsection{New Concepts Adopted from Another Culture}

It is easy to assume that because humans around the world share the same set of body parts, cultural imports do not exist for this semantic field. As has been shown in many cross-linguistic studies, speakers do not necessarily divide the human body in the same way (see Majid et al., 2006). For example, English refers to the area between the eye and the jaw bone as the 'cheek' but German divides this same area into Backe (the fleshy part) and Wange (the part closer to the eye). Likewise, both Irish and Hungarian refer to body parts that appear in pairs, such as the eyes, legs, or arms, as a single unit. Thus, to refer to only one arm, both Irish and Hungarian speakers will produce the equivalent of a 'half arm.' In the remainder of this section, I explore the following as potential sources for reconceptualizing the body: cultural imports including art and fashion, calques, and metaphors.

Cultural imports are not limited to objects but also include knowledge. For example, the Latin and Greek medical terms discussed in Section 3.1 above are not just examples of language prestige, but they can also be viewed as cultural imports of knowledge. Like science, art and fashion can trigger reconceptualization of the body motivating borrowings for body part terms.

The English term torso entered the language through Italian and was motivated by art. English speakers may also use the term trunk instead of torso and the terms core and midsection to refer to similar units of the body, but torso and trunk include the chest whereas core and midsection do not. As a unit, 
the torso has saliency by not being part of the limbs or head. This saliency may be influenced by clothing, as in many parts of the world it is covered with clothing (see Brown, 2005b; Brown and Witkowski, 1983, for more discussion of how clothing may influence body part nomenclature cross-linguistically). Art, especially sculptures, brought specific attention to the torso as a unit increasing its saliency. Before the renaissance, sculptures in Western art typically did not show much detail in their representation of the midsection of the human body. Sculptures in the renaissance brought attention to the torso, showing a much more realistic representation of it into art. Although English trunk indicates that there was already a conceptualization of this part of the body as a unit, imported forms of artwork brought a social medium to refer to this part of the body in a new way, giving rise to an opportunity to borrow the word through a cultural import. Interestingly, English speakers began extending torso to figurative speech quickly after it entered English (OED, 2O2O).

Fashion has also been a way to introduce new motivations to reconceptualize the body. Bator (2008) provides nine examples of semantic extensions from fashion to body parts and vice versa from Middle English to Modern English including girdle, mantle, and poke. Both mantle and poke entered English as borrowings. Mantle entered English via Latin and took on the meaning 'a lobe of a liver' and later 'a kind of tissue' in the 15th century. Poke likely entered English from either a French or Scandinavian origin to refer to a small bag. It later extended to refer to the stomach, and still retains this meaning in many dialects from Northern Ireland, Scotland, and England (p. 26o). For more widely known examples, both English and German have borrowed French décolletage. Originally referring to a low neckline in clothing that exposed bare shoulders, décolletage has extended to refer to the neck, shoulders, and upper bust as a single unit. Through fashion, these body parts have become a salient unit where before there was no reason to conceptualize this part of the body as a unit. German has also borrowed the word Taille 'waist' from French to refer to the waistline of clothing and now also to the backside of the waist. Compare this with German Mitte 'middle' or Bauch 'belly' which refer to overlapping areas within the concept 'waist.'

Calques are another source of cultural imports; however, they are not included in the WOLD data. Haspelmath (2009) differentiates between structural borrowing (including metaphors and calques) and loanwords; however, WOLD's focus is on loanwords, not structural borrowing. In the case of body parts as a semantic unit, ignoring structural borrowing overlooks many other examples of borrowings for referring to the body. As Campbell et al. (1986) claim, calques play a role in identifying Sprachbünde, and there are numerous 
body parts named by calques in Meso America. Examples of such calques appear below in (8).

Frequent Calques from Meso-American Languages

$\begin{array}{ll}\text { head of leg } & \text { 'knee' } \\ \text { neck of hand } & \text { 'wrist' } \\ \text { belly of leg } & \text { 'calf' } \\ \text { fruit/seed/bean of face } & \text { 'eye' } \\ \text { child of hand } & \text { 'finger' } \\ \text { mother of hand } & \text { 'thumb' } \\ \text { house (of) urine } & \text { 'bladder' } \\ \text { road (of blood) } & \text { 'vein' } \\ \text { grindstone (metate) } & \text { 'molar' } \\ \text { dog tooth, snake tooth } & \text { 'canine tooth' } \\ \text { bottle gourd (tecomate) } & \text { 'head' }\end{array}$

(Campbell et al., 1986: 553)

Of the examples given in (8) above, Campbell et al. write that the calques for 'knee', 'wrist', 'vein', 'molar', 'thumb', and 'finger' are most widely distributed among the languages they consider. Kaufman (2014) also identifies loanwords and calques for body parts in the languages of the Lower Mississippi Valley, including loanwords for anus/back, arm/hand, belly, breast, elbow, face, knee, mouth, tooth, and calques for thumb ('big/old hand') and vein ('blood house') (pp. 209-218). Likewise, Adelaar (1996) provides Malagasy voavitsy 'calf of the leg' as a derivative from the Malay compound buah batis which literally translates to 'fruit of the lower leg' (p. 487).

Ross (2007) shows how languages can further develop lexical calquing to other processes which he refers to a metatypy. To demonstrate this process, Ross provides multiple examples of lexical calques from Takia, an Austronesian language off the north coast of New Guinea modeled on Waskia, a completely unrelated Papuan language of the Trans-New Guinea family. Ross's examples appear below in (9) and (10).

(9) Corresponding Words with the Same Range of Meaning Takia Waskia

tatu sokel 'bone, strength'

nao-n koma 'his/her/its face, front, payment'

tini-n kumik 'his/her/its body, skin, bark, surface'

(Ross, 2007: 121) 
(10) Calques in Takia from Waskia as Source Language

\begin{tabular}{|c|c|c|}
\hline & Takia & Waskia \\
\hline 'the palm of my hand' & bani-g ate-n & a-gitiy gomay \\
\hline & hand-P:1s liver-P $\mathrm{P}_{3 \mathrm{~s}}$ & P:1S-hand $<\mathrm{P}: 3 \mathrm{~S}>$ liver \\
\hline '(an & runao-n & $m a$ \\
\hline$=$ 'face of word' & Word face-P:3S & ord $<\mathrm{P}: 3 \mathrm{~S}>$ face \\
\hline 'I an & mala-g & motam bete-sam \\
\hline out my eye' & eye-P: & eye do-S:3S \\
\hline 'I am & mala- & otam gerago-so \\
\hline goes round & S-go.round & eye go.round-S:3S \\
\hline 'I ob & $a w a-$ & kurig karotu-sam \\
\hline = 'I follow his mouth' & mouth-P:3S S:1S-follow & $<\mathrm{P}: 3 \mathrm{~S}>$ mouth follow-S:1S \\
\hline 'I dis & $a w a-$ & kuriy batugar-sam \\
\hline uth' & iS-cut & h cut-S:1S \\
\hline de him' & nao-n yu-futani & koma kalo-sam \\
\hline = 'I fence off his face' & face-P:3S S:1S-fence.off & $<\mathrm{P}: 3 \mathrm{~S}>$ face fence.off-S:1S \\
\hline 'I col & kukuc & dogowa ilu-sam \\
\hline$=$ 'I $\mathrm{l}$ & ear-P & $<\mathrm{P}: 3 \mathrm{~S}>$ ear hold-S:1S \\
\hline 'He believes (it)' & ilo-n lo rumok & 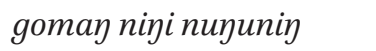 \\
\hline $\begin{array}{l}=\text { '(it is a) truth in his } \\
\text { guts' }\end{array}$ & $\begin{array}{l}\text { inside-P:3S POSTP:in } \\
\text { truth }\end{array}$ & $\begin{array}{l}<\mathrm{P}: 3 \mathrm{~S}>\text { liver POST } \mathrm{P}: \text { in } \\
\text { truth }\end{array}$ \\
\hline 'I am angry' & ilo-g saen & a-gemay memek \\
\hline 'my guts are bad' & inside-1SG bad & 1SG-liver bad \\
\hline
\end{tabular}

(Ross, 2007: 122)

Structural borrowing also plays a significant role in body part nomenclature cross-linguistically, especially for naming individual digits, the wrist, the ankle, and less salient body parts such as the heel of the hand. As Campbell et al.'s examples show, using kinship terms is one common way to refer to the digits. Brown and Witkowski (1981) discuss a similar pattern in North American languages. Pattillo (2014) also shows that this is a widespread pattern across the world's languages, along with patterns of extending some salient body parts, such as the head or eye to other parts of the body, such as the knee.

Returning to Irish, there are multiple complex terms to refer to individual fingers. For example, the ring finger can be called mac an aba [son of the abbot], mac an droma [son of the back], méar an fháinne [finger of the ring], or sisile. Of these four terms, méar an fháinne [finger of the ring] is the newest term and mirrors the pattern of English. The most frequent terms for the other individual fingers also mirror the naming patterns of English finger terms, even though there are other less common terms available. According to Brown and 
Witkowski (1981), European languages tend to use simplex terms for naming the digits. In fact, their data did not include examples of European languages with people terms used in naming the individual fingers. This suggests that Irish terms like mac an aba [son of the abbot], mac an droma [son of the back] are original native terms, but that méar an fháinne [finger of the ring] likely entered the language through contact.

As calques can be a rich source of borrowings to refer to the body, they should not be ignored. In some languages, body parts considered to be core vocabulary include calques. In many cases, body part terms named by figurative expressions should catch linguists' attention as sometimes they point to borrowings and other times, they demonstrate cross-linguistic tendencies. Haspelmath (2009) suggest that analyzable vocabulary such as 'younger sister' or 'day before yesterday', are not often borrowed because "they are often made from the resources from the language" (p. 45); however, the data presented in this paper suggest that calques are subject to the same social motivations as other types of borrowing. One possible motivator for borrowing calques rather than borrowed multiword units is the saliency of major body parts. Andersen (1978) suggests shape, position, and contiguity as three key characteristics of body part saliency. Since her classic cross-linguistic body part study, others have continued to apply these characteristics to body parts in semantic studies. For example, Kraska-Szlenk (2019b) writes these three features "are shared in the across-domain mapping" of the 'head' across languages (p. 138) and Pattillo (2019) uses them to explain how languages map the 'head' onto other body parts through multiword units, such as [leg head] 'knee' (found in Haida, Vietnamese, and possibly Hu) or 'foot' in Hungarian. Pattillo (2019: 131) suggests some languages extend 'head' to name the 'knee' and the 'foot' because they share features with the head, such as "shape (round) and position (out-most and upward depending on the body's posture)". Hence, borrowing calques further entrenches lexemes into the language and potentially employs cognitive mechanisms that may already exist in the language, such as metaphors, through saliency. Additionally, Haspelmath and Tadmor found that there are differences in counterparts for core vocabulary across languages. It is well known that languages also vary in how they name the body, thus a result of identifying "core vocabulary". Haspelmath and Tadmor's data do not include information regarding if recipient languages have also been donors to other languages. For example, loanwords from widely studied languages such as Latin or Chinese are common in the database, but there is no information about neighboring languages borrowing terms from the recipient languages. Although calques or infrequent cross-linguistic lexemes may not be helpful for identifying basic vocabulary or semantic primes, they are ideal for examining 
the social motivations for borrowings, which Thomason and Kaufman (1988) claim is the key factor of borrowing. Furthermore, they can play an important role in identifying a Sprachbund, as suggested by Campbell et al. (1986: $553-555)$.

The examples in this section show that language contact may trigger speakers to reconceptualize the body, especially with cultural imports such as science, art, and fashion. Polysemy and calques may also motivate borrowings.

\section{$5 \quad$ Further Discussion}

Thus far, I have presented factors that inhibit borrowing body part terms as well as motivations for loanword adoption. The data from the previous section demonstrate numerous examples of social motivations for borrowing terms for body parts. Although borrowings for body part terms may be much less frequent than other semantic domains, the patterns exhibited in the data presented in this paper follow the same patterns for any semantic domain. Having examined social motivations for loanword adoption, synonymy remains a factor needing more discussion. In Section 3, synonymy was an important factor in predicting lexical replacement. Synonyms show a general openness to lexical replacement, and loanwords can provide one of the word formation processes in such replacements. Taboo is an obvious area motivated by social factors to have synonymy in body parts, thus the high percentages of languages in the WOLD sample with loanwords for genitalia, reproduction, and death is not surprising. In contrast, "basic" body parts like the head and hand have high frequency in language production, but corpus-based studies illustrate they also have synonyms. Kraska-Szlenk (2014) and Gąsiorowski (2017) show examples of synonyms for these terms in Polish and English, respectively. Although one term is more neutral for referring to the head or hand in each of their examples given, the fact that highly frequent lexemes for basic body parts are often synonymous suggests some level of openness for lexical replacement for body parts.

Body parts are frequently sources for metonymic, metaphoric, and grammatical extensions cross-linguistically. Returning to the question posed in Section 2 regarding extensions of frequently used terms compared to coexisting ones, it seems that there are examples of both. Some coexisting terms can be used interchangeably in extensions, such as metaphors. The example of English nose and schnoz show that they are similar with subtle differences, but extensions have occurred through the word nose, not through schnoz. In this example, pragmatic factors likely lead to a speaker selecting nose or schnoz 
in an utterance. In more neutral contexts, metaphor studies suggest that synonymous lexemes for body parts undergo different pathways of semantic change. Here I present examples from German, Modern Greek and Turkish for consideration.

In German, the borrowing Kopf (from Vulgur Latin) has replaced the native Haupt as the term for 'head'. Despite this replacement, both terms have triggered numerous extensions, exemplified below in (11).

(11) a. Extensions with Kopf

$\begin{array}{ll}\text { Salatkopf, Kohlkopf } & \text { 'head of lettuce, head of cabbage' } \\ \text { Kopfbahnhof } & \text { 'terminal train station' } \\ \text { Kopfwäsche } & \text { 'hair wash' } \\ \text { Kopfzeile } & \text { 'headlines' } \\ \text { kopfüber } & \text { 'headfirst' } \\ \text { b. Extensions with Haupt } & \\ \text { Salathäuptel } & \text { 'head of lettuce' (Austrian dialect) } \\ \text { Hauptbahnhof } & \text { 'main train station' } \\ \text { Haupthaar } & \text { 'hair of head or scalp' } \\ \text { Hauptstadt } & \text { 'capital city' } \\ \text { Hauptsitz } & \text { 'headquarters' } \\ \text { Hauptsache } & \text { 'main point' }\end{array}$

These examples show that both Kopf and Haupt share overlapping but not identical targets. They both extend to round objects, but Haupt is extended more frequently to show dominance or importance whereas the Kopf extensions given above focus on physical location. Siahaan (2011) further shows the differences between Kopf and Haupt, stating that Kopf also extends as the metonymies for LEADER and PART FOR WHOLE, and the metaphors LOCUS OF THOUGHT, THE HEAD IS A USEFUL INSTRUMENT, TEMPERATURE, and THE HEAD IS A CONTAINER. Haupt is generally used to denote MAIN/IMPORTANT and can be combined with ober- 'upper' as a metonym for LEADER (pp. 95100). Thus, the newer, borrowed term for 'head' has become more entrenched in the language than the older native Germanic one.

Examples from Turkish show different targets for head extensions as well. Turkish has five lexemes meaning 'head'. Two of them are native Turkic ones, but the other three are loanwords coming from Arabic and Persian. Like in the German example above, although the Turkish lexemes are interchangeable in some contexts, they differ in other usages. Three of the lexemes are highly restricted in usage. Mutlu et al. (2019) found that although baş (from Turkic) and $k a f a$ (from Arabic) can both refer to the entire head, semantic extensions of the two show baş specifically refers to the internal part of the head and kafa 
to the external. Baş extends to mean 'leader', 'main', 'top', 'tip', 'position' and has a more neutral meaning, whereas kafa extends metaphorically to represent the mind, memory, part of a mechanism, or mentality. Unlike baş, kafa tends to have a negative/absurd connotation (p. 213).

Similar findings have been reported for synonymous lexemes meaning 'face.' Marmaridou (2011) states that of six lexemes for Modern Greek 'face', five are borrowed from Italian, Latin, and Venetian (p. 24). Although Marmaridou does not further analyze these five loanwords for 'face' in her study, she states that they each demonstrate metonymic and metaphoric extensions and occur in idioms and collocations with high frequency. She claims native Greek prosopo 'face' occurs most frequently of the six terms, whereas the five loanwords for 'face' represent a broad range of registers and styles (p. 24). Turkish shows similar differences in frequency in how its three counterparts of 'face' occur within the domain емотіол. Turkish yüz, surat, and çehre 'face' come from Turkic, Arabic, and Persian, respectively. Turkic yüz is the more versatile of the three 'face' counterparts. Baş (under review) shows yüz occurs in expressions for thirteen different emotions, but occurrences of surat and çehre are much more restricted in emotional usages, often referring to negative emotions such as shame and sadness. When expressing anger, Baş found fifty-three occurrences of surat in her corpus data, but only six occurrences each of çehre and yüz.

From these examples, languages entrench synonymous body part lexemes in different ways. Loanwords may overlap with native terms denoting body parts, but it seems speakers use them to express different nuances that are further accentuated through semantic extension. The German example of Haupt and Kopfdemonstrates that even in lexical replacement of a "major" body part, loanwords for body parts carry different metaphoric usages. In some cases, such as in the example of German Kopf, the loanword extends much more broadly within the language. In other cases, such as in Turkish and Modern Greek, synonymous loanwords for 'face' and 'head' are more restricted than the native term(s) with which they co-exist.

In addition to loanwords triggering different semantic extensions, such as metaphor, language contact can also lead to borrowing metaphors to name less salient body parts. Brown and Witkowski (1981) list multiple examples of shared metaphors in body part names around the world's languages. These include using terms for humans to refer to the pupils of the eye, kinship terms to refer to the digits, eggs or stones to refer to the testicles, and small mammals or lizards to refer to muscular parts of the body, such as the calf of the leg or the biceps. For example, English muscle is from a diminutive form of Latin musculus 'little mouse' (p. 6o2). Although the data Brown and Witkowski (1981) provide clearly demonstrate a widespread tendency to use these metaphors 
cross-linguistically, they also mention clear examples of borrowing in their data, such as Zapotec and Tequistlatec both borrowing the term niño 'child' from Spanish and then extending it as Spanish does to name the pupil combined with native terms. This shows that language speakers borrow figurative language along with individual lexemes.

Finally, the analysis provided in this paper considers a variety of social factors and some pragmatic factors, such as prestige and taboo, but it is not exhaustive. There are other aspects that could be considered in future research on loanwords for body parts as well as loanwords in general. These include pragmatic factors in both code-switching among bilinguals and choice of lexemes when body parts have synonymous terms. As an anonymous reviewer suggests, the literature in both code-switching and lexeme selection from different registers offer additional insight into the processes that motivate borrowing. Although outside of my own area of expertise, these ideas support the potential benefit of considering lexical change from multiple theoretical approaches.

\section{Conclusion}

It is well-known that the origin and survival of language structures are motivated by different desiderata that are sometimes in conflict. What linguists may reasonably aim at is identifying the most likely motivations that play a role. Explaining how the conflicts among the different motivations are resolved such as what trumps what or what compromise is reached - is difficult if possible, at all. Cases of linguistic conflict present the question how do languages weigh various factors? For example, if prestige of another language is a factor, why does it not always outweigh factors that militate against borrowing body part terms, such as frequency? These are important and intriguing questions even though I am not taking on the task of trying to resolve them here.

This paper aimed to identify and detail the factors at play in inhibiting and motivating the borrowing of body part lexemes. I asked two guiding research questions, repeated below.

1. Why do languages borrow body parts less frequently than other semantic fields?

2. What, given these factors, motivates languages to borrow words for body parts?

Body parts are often entrenched in languages through metonymy and metaphor. They are frequent in language, they are often older terms in a language, and they are highly imageable. These factors make them resistant to borrowing. 
These factors help explain why, cross-linguistically, languages borrow body parts less frequently than other semantic fields.

Although body parts may be borrowed less frequently than other semantic fields, the data highlighted here demonstrate that languages actively borrow body part lexemes for a variety of reasons, including social and pragmatic factors. The data also show that although there are no new body parts to name, languages may reconceptualize the body and its divisions creating a gap in vocabulary. Thus, borrowings occur for both frequently named body parts, such as the head or the ear as well as newly conceptualized divisions of the body, such as the décolletage. In summary, body parts can be reconceptualized. They often coexist with other words for the same reference point, and they can become socially stigmatized. Furthermore, they provide interesting examples of lexical borrowings and calques that may further aid in the identification of Sprachbünde.

Haspelmath and Tadmor (2009a) suggest core vocabulary, which includes body parts, is difficult to borrow; however, their data and findings open the door for further analysis from a social interaction viewpoint. Of the semantic categories listed in WOLD, the categories with the highest percentage of loanwords are clear examples of social factors motivating borrowings: religion and beliefs, clothing and grooming, the house, law, and social and political relations. Although the body as a semantic field typically has lower frequency of borrowings, the examples presented here demonstrate a wide variety of motivations for borrowing lexemes for body parts. This suggests that social factors promote borrowings regardless of semantic field and these borrowings follow the same patterns across languages.

Finally, body parts as loanwords by themselves should not alarm linguists working on language documentation projects, as they are not necessarily a sign of language vitality, as suggested by Vrzić and Doričić (2014). It is common for body part borrowings to coexist with native lexemes in many languages and social prestige is one of the factors that motivates such borrowings.

\section{References}

Adelaar, K. A. 1996. Malagasy culture-history: some linguistic evidence. In Julian Reade (ed.), The Indian Ocean in Antiquity: Indian (Ocean) History, 487-50o. London: Kegan Paul International.

Andersen, Elaine S. 1978. Lexical universals of body part terminology. In Joseph H. Greenberg (ed.), Universals of Human Language: Word Structure, vol. 3, 335-368.

Stanford: Stanford University Press. 
Baş, Melike. Under review. The embodiment of emotions in Turkish face constructions. In Kelsie Pattillo and Małgorzata Waśniewska (eds.), Embodiment in Cross-Linguistic Studies: The 'Face'.

Bator, Magdalena. 2008. 'Parts of the body' and 'parts of clothing'; a semantic analysis. Historical Englishes in varieties of texts and contexts; the Global COE Programme, international conference 2007, 259-267. Frankfurt am Main: Peter Lang.

Brown, Cecil H. 1999. Lexical acculturation in Native American languages. New York: Oxford University Press.

Brown, Cecil H. 2001. Lexical typology from an anthropological point of view. In Martin Haspelmath, Ekkehard König, Wult Oesterreicher and Wolfgang Raible (eds.), Language typology and language universals; an international handbook, vol. 2, 1178119o. Berlin: De Gruyter.

Brown, Cecil H. 2005a. Finger and Hand. In Martin Haspelmath (ed.), The World Atlas of Language Structures. Online: http://wals.info/feature/description/130.

Brown, Cecil H. 2005b. Hand and Arm. In Martin Haspelmath (ed.), The World Atlas of Language Structures. Online: http://wals.info/feature/description/129.

Brown, Cecil H. and Stanley Witkowski. 1981. Figurative language in a universalist perspective. American Ethnologist 8: 596-615. DOI: 10.1525/ae.1981.8.3.02aool1o.

Brown, Cecil H. and Stanley Witkowski. 1983. Polysemy, lexical change, and cultural importance. Man 18: 72-89. DOI: 10.2307/2801765.

Campbell, Lyle, Terrence Kaufman and Thomas Smith-Stark. 1986. Meso-America as a linguistic area. Language 62(3): 530-570. DOI: 10.2307/415477.

Corpus of Contemporary American English. (Available online at http://English-Corpora. org/COCA/, accessed on o6-29-2020).

Corpus of Contemporary Irish. (Available online at http://gaois.ie/, access on o6-29-2020).

Dixon, R.M.W. 1990. The origin of "mother-in-law vocabulary" in two Australian languages. Anthropological Linguistics 32(1/2): 1-56.

Enfield, Nicholas J. 2006. Lao body part terms. Language Sciences 28(2-3): 181-200. DOI: 10.1016/j.langsci.2005.11.011.

Gąsiorowski, Piotr. 2017. The embarrassment of riches: head words in the IndoEuropean family. Yearbook of the Poznan Linguistic Meeting 3: 101-115. DOI: http:// dx.doi.org/10.1515/yplm-2017-0005.

Grant, Anthony. 2009. English vocabulary. In Martin Haspelmath and Uri Tadmoor (eds.), World Loanword Database. Leipzig: Max Planck Institute for Evolutionary Anthropology. (Available online at http://wold.clld.org, accessed on 02-23-2019).

Harris, Alice. 2010. Explaining typologically unusual structures: the role of probability. In Jan Wohlgemuth and Michael Cysouw (eds.), Rethinking Universals. How Rarities Affect Linguistic Theory, 91-103. Berlin: De Gruyter. 
Haspelmath, Martin. 2009. Lexical borrowing: concepts and issues. In Martin Haspelmath and Uri Tadmoor (eds.), Loanwords in the World's Languages: A Comparative Handbook, 35-54. Berlin: De Gruyter. DOI: 10.1515/9783110218442.35.

Haspelmath, Martin and Uri Tadmor (eds.). 20oga. Loanwords in the World's Languages: A Comparative Handbook. Berlin: De Gruyter.

Haspelmath, Martin and Uri Tadmor (eds.). 20ogb. World Loanword Database. Leipzig: Max Planck Institute for Evolutionary Anthropology. (Available online at http:// wold.clld.org, accessed on O2-23-2019).

Heine, Bernd and Tania Kuteva. 2008. Constraints in contact-induced linguistic change. Journal of language contact, Thema 2, 57-9o. DOI: 10.1163/oooooooo8792525363.

Helmbrecht, Johannes. 2005. Typologie und Diffusion von Höflichkeitspronomina in Europa. Folia Linguistica 39(3-4): 417-452.

Hilpert, M. 2007. Chained Metonymies in Lexicon and Grammar: A Cross-Linguistic Perspective on Body Part Terms. In Günter Radden, Klaus-Michael Köpcke, Thomas Berg and Peter Siemund (eds.), Aspects of Meaning Construction, 77-98. Amsterdam, Netherlands: Benjamins.

Holman, Eric W., Soren Wichman and Cecil H. Brown. 2008. Explorations in automated language classification. Folia linguistica 42(2): 331-354.

Kaufman, David V. 2014. The Lower Mississippi Valley as a Language Area. Doctoral dissertation, University of Kansas.

Key, Mary Ritchie and Bernard Comrie (eds.). 2015. The Intercontinental Dictionary Series. Leipzig: Max Planck Institute for Evolutionary Anthropology. (Available online at http://ids.clld.org, accessed on 11-28-2020).

Kossmann, Maarten. 20o9. Tarifiyt Berber vocabulary. In Martin Haspelmath and Uri Tadmoor (eds.), World Loanword Database. Leipzig: Max Planck Institute for Evolutionary Anthropology. (Available online at http://wold.clld.org, accessed on O2-23-2019).

Kraska-Szlenk, Iwona. 2014. Semantics of Body Part Terms: General Trends and a Case Study Swahili. Munich: Lincolm.

Kraska-Szlenk, Iwona (ed.). 2019a. Embodiment in Cross-Linguistic Studies: The 'Head'. Leiden: Brill.

Kraska-Szlenk, Iwona (ed.). 2019b. Metonymic extensions of the body part 'head' in mental and social domains. In Iwona Kraska-Szlenk (ed.), Embodiment in CrossLinguistic Studies: The 'Head'. Leiden: Brill. DOI: 10.1163/9789004392410_oog.

Krefeld, Thomas. 1999. Cognitive ease and lexical borrowing: the recategorization of body parts in Romance. In Andreas Blank and Peter Koch (eds.), Historical Semantics and Cognition, 259-277. Berlin: De Gruyter, Inc.

Maalej, Zouheir A. and Ning Yu (eds.). 2011. Embodiment via Body Parts: Studies from Various Languages and Cultures. Amsterdam:John Benjamins Publishing Company. 
Majid, Asifa. 2010. Words for parts of the body. In Barbara C. Malt and Phillip Wolff (eds), Words and the Mind, 58-71. Oxford: Oxford University Press.

Majid, Asifa, Nicholas J. Enfield and Miriam van Staden (eds.). 2006. xx. Language Sciences 28(2-3): 137-36o.

Marmaridou, Sophia. 2011. The relevance of embodiment to lexical and collocational meaning: The case of prosopo 'face' in Modern Greek. In Zouheir Maalej and Ning Yu (eds.), Embodiment via Body Parts: Studies from Various Languages and Cultures, 23-40. Amsterdam: John Benjamins Publishing Company.

Mutlu, Feliz, Aysel Kapan, Ali Yagiz Sen, Hilal Yildirim-Gündoğdu, and Asli Göksel. 2019. 'Head' idioms in Turkish: contrasts and correlations. In Iwona Kraska-Szlenk (ed.), Embodiment in Cross-Linguistic Studies: The 'Head', 205-218. Leiden: Brill.

Onysko, Alexander and Esme Winter-Froemel. 2011. Necessary loans- luxury loans? Exploring the pragmatic dimension of borrowing. Journal of Pragmatics 43: 15501567. DOI: 10.1016/j.pragma.2010.12.004.

OxfordEnglishDictionary. (Available online at http://oed.com, accessed on o6-29-2020).

Pagel, Mark, Quentin D. Atkinson and Andrew Meade. 2007. Frequency of worduse predicts rate of lexical evolution throughout Indo-European history. Nature 449(7163): 717-720. DOI: 10.1038./natureo6176.

Pattillo, Kelsie. 2014. Cross-linguistic metonymies in human limb nomenclature. Doctoral dissertation, University of Wisconsin-Milwaukee.

Pattillo, Kelsie. 2019. From head to toe: how languages extend the head to name body parts. In Iwona Kraska-Szlenk (ed.), Embodiment in Cross-Linguistic Studies: The 'Head'. Leiden: Brill. DOI: 10.1163/9789004392410_oo8.

Pizarro Pidraza, Andrea. 2018. Calling things by their name: exploring the social meanins in the preference for sexual (in)direct construals. In Andrea Pizarro Pedraza (ed.), Linguistic Taboo Revisited: Novel Insights from Cognitive Perspectives, 245-268. Berlin: Walter De Gruyter.

Richie Key, Mary and Bernard Comrie (eds.). 2015. Intercontinental Dictionary Series. Leipzig: Max Planck Institute for Evolutionary Anthropology. (Available online at http://ids.clld.org).

Ross, Malcom. 2007. Calquing and Metatypy. Journal of Language Contact 1: 116-143. DOI:10.1163/oooooooo779258341.

Schmidt, Christopher. 2009. Japanese vocabulary. In Martin Haspelmath and Uri Tadmoor (eds.), World Loanword Database. Leipzig: Max Planck Institute for Evolutionary Anthropology. (Available online at http://wold.clld.org, accessed on o2-23-2019).

Sharifian, Farzad, René Dirven, Ning Yu, and Susanne Niemeier (eds.). 2008. Culture, Body, and Language: Conceptualizations of Internal Body Organs across Cultures and Languages. Berlin, New York: Mouton De Gruyter. 
Siahaan, Poppy. 2011. Head and eye in German and Indonesian figurative uses. In Zouheir A. Maalej and Ning Yu (eds.), Embodiment via Body Parts: Studies from Various Languages and Cultures, 93-113. Amsterdam: John Benjamins Publishing Company.

Suthiwan, Titima. 20o9. Thai vocabulary. In Martin Haspelmath and Uri Tadmoor (eds.), World Loanword Database. Leipzig: Max Planck Institute for Evolutionary Anthropology. (Available online at http://wold.clld.org, accessed on 02-23-2019).

Swadesh, Morriss. 1952. Lexico-statistical dating of prehistoric ethnic contacts: with special reference to North American Indians and Eskimos. Proceedings of the American Philosophical Society 96, 452-463.

Sweetser, Eve. 199o. From Etymology to Pragmatics. New York: Cambridge University Press.

Tadmor, Uri. 20o9. Loanwords in the World's Languages: Findings and Results. In Haspelmath Martin, and Uri Tadmor (eds.), Loanwords in the World's Languages: A Comparative Handbook. Berlin: De Gruyter.

Thomason, Sarah G. 2008. Social and linguistic factors as predictors of contact-induced change. Journal of language contact. Thema 2, 42-56. DOI: 10.1163/oooooooo8792525381.

Thomason, Sarah G. and Terrence Kaufman 1988. Language contact, creolization, and genetic linguistics. Berkeley - Los Angeles: University of California Press.

Vejdemo, Susanne and Thomas Hörberg. 2016. Semantic factors predict the rate of lexical replacement of content words. PLoS ONE 11(1): e0147924. DOI: 10.1371/ journal.pone.0147924.

Vrzić, Zvjezdana and Robert Doričić. 2014. Language contact and stability of basic vocabulary: Croation loanwords for body parts in Vlashki/Zheyanski (IstroRomanian). Flumensia 26: 105-122.

Wierzbicka, Anna. 2007. Bodies and their parts: an NSM approach to semantic typology. Language Sciences 29: 14-65. DOI: 10.1016/j.langsci.2006.07.002.

Wierzbicka, Anna and Cliff Goddard. 2018. Talking about our Bodies and their Parts in Warlpiri. Australian Journal of Linguistics 38: 31-62. DOI: 10.1080/072686o2.2018.1393862.

Wilkins, David P. 1996. Semantic Change and the Search for Cognates. In Mark Durie and Malcom Ross (eds.), The Comparative Method Reviewed: Regularity and Irregularity in Language Change, 264-304. New York: Oxford University Press.

Winter Froemel, Esme. 2014. Formal variance and semantic changes in borrowing: integrating semasiology and onomasiology. In Eline Zenner et al. (eds.), New Perspectives on Lexical Borrowing: Onomasiological, Methodological and Phraseological Innovations, 65-100. Berlin: De Gruyter, Inc.

Witkowski, Stanley and Cecil H. Brown. 1985. Climate, clothing and body-part nomenclature. Ethnology 24: 197-214. DOI: 10.2307/3773610. 


\section{Appendix}

\section{wOLD Vocabulary Terms: The Body}

The following vocabulary terms appear within the semantic field 'the body' in both WOLD and the Intercontinental Dictionary Series (Key and Comrie, 2015). These terms include lexemes for conceptualizing the body as well as those associated with the body, such as 'to breathe', 'healthy', or 'naked'.

Body, skin or hide, flesh, hair, beard, body hair, pubic hair, dandruff, blood, vein or artery, bone, rib, horn, tail, back, spine, head, temple, skull, brain, face, forehead, jaw, cheek, chin, eye, eyebrow, eyelash, blink, ear, earlobe, earwax, nose, nostril, nasal mucus, mouth, beak, lip, tongue, tooth, gums, molar tooth, neck, nape of the neck, throat, shoulder, shoulder blade, arm, armpit, elbow, wrist, hand, pal of the hand, finger, thumb, fingernail, claw, leg, thigh, calf of the leg, knee, foot, ankle, heel, footprint, toe, wing, feather, chest, breast, nipple, teat, udder, navel, belly, heart, lung, liver, kidney, spleen, stomach, intestines, waist, hip, buttocks, sinew or tendon, womb, testicle, penis, vagina, vulva, to breathe, to yawn, to hiccough, to cough, sneeze, to perspire, to spit, to vomit, to bite, to lick, to dribble, to sleep, to snore, to dream, to wake up, to fart, to piss, to shit, to have sex, to shiver, to bathe, to beget, to be born, pregnant, to conceive, to be alive, life, to die, dead, to drown, to kill, corpse, carcass, to bury, grave, strong, weak, healthy, sick or ill, fever, goiter, cold, wound, bruise, swelling, itch, scratch, blister, boil, puss, scar, to cure, physician, medicine, poison, tired, to rest, lazy, bald, lame, deaf, mute, blind, drunk, naked.

\section{WOLD Languages and Body Part Loanword Percentages}

The following languages and percentages appear in the individual chapters of Loanwords in the World's Languages: A Comparative Handbook (Haspelmath and Tadmore, 2009a) and wOLD (Haspelmath and Tadmor, 2009b). The percentages given represent the number of the loanwords out of the total words given for each semantic field. 


\begin{tabular}{|c|c|c|}
\hline Language & $\begin{array}{l}\text { Percentage of Body } \\
\text { Part terms as } \\
\text { Loanwords }\end{array}$ & $\begin{array}{l}\text { Semantic Fields with Fewer Loan- } \\
\text { words, by Percentage }\end{array}$ \\
\hline Selice Romani & 57.2 & $\begin{array}{l}\text { Possession (51.2), Spatial Relations } \\
\text { (47.7), Quantity (37.0), Kinship (32.1), } \\
\text { Misc. Function Words (12.8) }\end{array}$ \\
\hline Gurindji & 42.4 & $\begin{array}{l}\text { Spatial Relations (37.3), Quantity } \\
(33 \cdot 3) \text {, Social and Political Relations. } \\
(33 \cdot 3) \text {, Time (31.6), The House (28.2), } \\
\text { Religion and Belief (28.2), Emotions } \\
\text { and Values (26.4), Cognition (26.3), } \\
\text { Misc. Function Words }(8.5)\end{array}$ \\
\hline Romanian & 39.2 & $\begin{array}{l}\text { Food and Drink (30.9), Motion (35.1), } \\
\text { Time (25.3), Spatial Relations }(24 \cdot 3) \text {, } \\
\text { Kinship (23.1), Quantity (17.7), Sense } \\
\text { Perception (13.9), Misc. Function } \\
\text { Words (6.5) }\end{array}$ \\
\hline Saramaccan & 35.2 & $\begin{array}{l}\text { Time (34), Animals }(32.6) \text {, Sense } \\
\text { Perception (32.4), The House (31.2), } \\
\text { Warfare and hunting }(29.5) \text {, Religion } \\
\text { and Belief }(25.6) \text {, Social and Political } \\
\text { Relations }(24.7)\end{array}$ \\
\hline Thai & 30.4 & $\begin{array}{l}\text { Emotions and Values (25.9), Cognition } \\
(25 \cdot 5) \text {, Agriculture and vegetation (24), } \\
\text { Speech and Language (22.6), Warfare } \\
\text { and Hunting (21.1), Sense Perception } \\
\text { (20.3), Motion (19.2), Clothing and } \\
\text { Grooming (18.8), Possession (18.8), } \\
\text { Food and Drink (17.9), Kinship (15.5), } \\
\text { Spatial Relations (10.2), Misc. Function } \\
\text { Words (o) }\end{array}$ \\
\hline Tarifiyt & $29 \cdot 5$ & Misc. Function Words (21.7) \\
\hline Japanese & 29.2 & $\begin{array}{l}\text { Animals (24.7), Motion (19.4), Spatial } \\
\text { Relations (16.2), Misc. Function Words } \\
\text { (9.8), Sense Perception (7.4) }\end{array}$ \\
\hline British English & 28.1 & $\begin{array}{l}\text { Time (18.0), Quantity (13.2), Misc. } \\
\text { Function Words (7.1) }\end{array}$ \\
\hline
\end{tabular}




\begin{tabular}{|c|c|c|}
\hline Language & $\begin{array}{l}\text { Percentage of Body } \\
\text { Part terms as } \\
\text { Loanwords }\end{array}$ & $\begin{array}{l}\text { Semantic Fields with Fewer Loan- } \\
\text { words, by Percentage }\end{array}$ \\
\hline Indonesian & 24.2 & $\begin{array}{l}\text { Motion (19), Quantity (18.4), Sense Per- } \\
\text { ception (16.7), Misc. Function Words } \\
\text { (16.3), Spatial Relations (15.2) }\end{array}$ \\
\hline Ceq Wong & 21.9 & $\begin{array}{l}\text { Spatial Relations (21.7), Kinship (20.3), } \\
\text { Sense Perception (19.2), Misc. Function } \\
\text { Words (19) }\end{array}$ \\
\hline Vietnamese & $19 \cdot 4$ & $\begin{array}{l}\text { Misc. Function Words (18.5), Animals } \\
\text { (14.8), Quantity (15.0), Sense Percep- } \\
\text { tion (12.0) }\end{array}$ \\
\hline $\begin{array}{l}\text { Imbabura Que- } \\
\text { chua }\end{array}$ & 17.0 & $\begin{array}{l}\text { Speech and Language (16.6), Cogni- } \\
\text { tion (15.7), Warfare and hunting (15.0), } \\
\text { Motion (14.4), The Physical World } \\
(10.6) \text {, Quantity (2.5), Misc. Function } \\
\text { Words (2.0) }\end{array}$ \\
\hline Kanuri & 14.76 & $\begin{array}{l}\text { Kinship (13.51), Motion }(7 \cdot 5) \text {, Function } \\
\text { Words }(7 \cdot 14) \text {, Spatial Relations }(5 \cdot 55) \text {, } \\
\text { Emotions and Values }(5 \cdot 4) \text {, Misc. Func- } \\
\text { tion Words }(5 \cdot 4) \text {, Sense Perception } \\
(5 \cdot 1) \text {, }\end{array}$ \\
\hline Lower Sorbian & 14.6 & $\begin{array}{l}\text { Motion (13.0), Spatial Relations (8.4), } \\
\text { Time (8.3), Law }(3.2)\end{array}$ \\
\hline Sakha (Yakut) & 14.5 & $\begin{array}{l}\text { Spatial Relations (13.9), Sense Percep- } \\
\text { tion }(4 \cdot 5) \text {, Misc. Function Words (o) }\end{array}$ \\
\hline Bezhta & 13.9 & $\begin{array}{l}\text { Spatial Relations (13.9), Sense Percep- } \\
\text { tion }(3.2) \text {, Mis. Function Words (o) }\end{array}$ \\
\hline Malagasy & 12.2 & $\begin{array}{l}\text { Spatial Relations (12.3), Social and } \\
\text { Political Relations (12.2), Time (11.6), } \\
\text { Misc. Function Words (11.4), Warfare } \\
\text { and Hunting (10.5), Cognition (9.9), } \\
\text { Emotions and Values (4) }\end{array}$ \\
\hline $\begin{array}{l}\text { Nakh-Dagh- } \\
\text { estanian }\end{array}$ & 12.1 & $\begin{array}{l}\text { Motion (11.8), Sense Perception (2.2), } \\
\text { Misc. Function Words (o) }\end{array}$ \\
\hline
\end{tabular}




\begin{tabular}{|c|c|c|}
\hline Language & $\begin{array}{l}\text { Percentage of Body } \\
\text { Part terms as } \\
\text { Loanwords }\end{array}$ & $\begin{array}{l}\text { Semantic Fields with Fewer Loan- } \\
\text { words, by Percentage }\end{array}$ \\
\hline $\begin{array}{l}\text { Sychelles } \\
\text { Creole }\end{array}$ & 11.9 & $\begin{array}{l}\text { Law (10.4), Clothing and Grooming } \\
(10.3) \text {, Sense Perception (9.0), Speech } \\
\text { and Language ( } 8.7) \text {, Spatial Quantity } \\
\text { (7.7), Possession (7.5), Agriculture and } \\
\text { Vegetation (7.4), Basic Actions and } \\
\text { Technology (7.3), Motion (5.5), Rela- } \\
\text { tions (5.5), The Physical World (4.5), } \\
\text { Kinship (4.2), Emotions and Values } \\
\text { (4.2), Cognition (4.0), Social and Polit- } \\
\text { ical Relations (3.4), Time (0.0), Misc. } \\
\text { Function Words (0) }\end{array}$ \\
\hline Swahili & $9 \cdot 9$ & $\begin{array}{l}\text { Animals (9.8), Miscellaneous Function } \\
\text { Words (7.1) }\end{array}$ \\
\hline Dutch & $9 \cdot 7$ & $\begin{array}{l}\text { Kinship (7.4), Quantity (5.1), Sense } \\
\text { Perception (4.0), Law (3.8), Misc. Func- } \\
\text { tion Words (o) }\end{array}$ \\
\hline White Hmong & 6.1 & Kinship (5.2) \\
\hline Yaqui & $5 \cdot 9$ & $\begin{array}{l}\text { Kinship (2.7), Sense Perception (o), } \\
\text { Misc. Function Words (o) }\end{array}$ \\
\hline Zinacantán & $5 \cdot 9$ & $\begin{array}{l}\text { Misc. Function Words }(7 \cdot 7) \text {, Sense } \\
\text { Perception (4.1), Motion (3.7) }\end{array}$ \\
\hline Q'eqchi' & 4.8 & $\begin{array}{l}\text { Sense Perception (4.8), Quantity }(3 \cdot 3) \text {, } \\
\text { Emotions and Values (1.6), Misc. Func- } \\
\text { tion Words (o) }\end{array}$ \\
\hline Mapudungun & 4.6 & Misc. Function Words (o) \\
\hline Ket & $3 \cdot 3$ & $\begin{array}{l}\text { Kinship (1.5), Sense Perception, Speech } \\
\text { and Language (o), Misc. Function } \\
\text { Words (o.o) }\end{array}$ \\
\hline Otomi & 3.2 & Sense Perception (1.2) \\
\hline Iraqw & 3.1 & $\begin{array}{l}\text { Spatial Relations (2.4), Sense Per- } \\
\text { ception (2.1), Emotions and Values } \\
\text { (o), Quantity (o), Social and Political } \\
\text { Relations (o), Miscellaneous Function } \\
\text { Words (o) }\end{array}$ \\
\hline Takia & 2.5 & $\begin{array}{l}\text { Kinship (2.3), Emotions and Values (o), } \\
\text { Misc. Function Words (o) }\end{array}$ \\
\hline
\end{tabular}




\begin{tabular}{|c|c|c|}
\hline Language & $\begin{array}{l}\text { Percentage of Body } \\
\text { Part terms as } \\
\text { Loanwords }\end{array}$ & $\begin{array}{l}\text { Semantic Fields with Fewer Loan- } \\
\text { words, by Percentage }\end{array}$ \\
\hline Hawaiian & 2.1 & $\begin{array}{l}\text { Emotions and Values (o), Warfare and } \\
\text { Hunting (o), Misc. Function Words (o) }\end{array}$ \\
\hline Hup & 1.4 & \\
\hline Wichí & 0.7 & $\begin{array}{l}\text { Emotions and Values (o.o), Misc. Func- } \\
\text { tion Words (o.o) }\end{array}$ \\
\hline $\begin{array}{l}\text { Old High Ger- } \\
\text { man }\end{array}$ & 0.7 & $\begin{array}{l}\text { Kinship (o.o), Quantity (o.o), Time } \\
\text { (o), Sense Perception (o), Emotions } \\
\text { and Values (o), Social and Political } \\
\text { Relations (o), Misc. Function Words } \\
\text { (all o.o) }\end{array}$ \\
\hline $\begin{array}{l}\text { Mandarin } \\
\text { Chinese }\end{array}$ & 0.0 & \\
\hline Kali'na & 0.0 & $\begin{array}{l}\text { Kinship (o), Sense Perception (o), } \\
\text { Misc. Function Words (o) }\end{array}$ \\
\hline
\end{tabular}

